\title{
Fifty years of brain imaging in neonatal encephalopathy following perinatal asphyxia
}

\author{
Floris Groenendaal ${ }^{1}$ and Linda S. de Vries ${ }^{1}$
}

In the past brain imaging of term infants with hypoxic-ischemic encephalopathy (HIE) was performed with cranial ultrasound (cUS) and computed tomography (CT). Both techniques have several disadvantages sensitivity and specificity is limited compared with magnetic resonance imaging (MRI) and CT makes use of radiation. At present MRI including diffusion weighted MRI during the first week of life, has become the method of choice for imaging infants with HIE. In addition to imaging, blood vessels and blood flow can be visualized using MR angiography, MR venography, and arterial spin labeling. Since the use of these techniques additional lesions in infants with $\mathrm{HIE}$, such as arterial ischemic stroke, sinovenous thrombosis, and subdural hemorrhages can be diagnosed, and the incidence appears to be higher than shown previously. Phosphorus magnetic resonance spectroscopy (MRS) has led to the concept of secondary energy failure in infants with HIE, but has not been widely used. Proton MRS of the basal ganglia and thalamus is one of the best predictors of neurodevelopmental outcome. cUS should still be used for screening infants admitted to a $\mathrm{NICU}$ with neonatal encephalopathy. In the future magnetic resonance techniques will be increasingly used as early biomarkers of neurodevelopmental outcome in trials of neuroprotective strategies.

D uring the last 50 y research in term infants with hypoxicischemic encephalopathy (HIE) has made a tremendous progress resulting in supportive care with mechanical ventilation, circulatory support, extracorporeal membrane oxygenation in selected cases, improved neuromonitoring, and the use of hypothermia as a neuroprotective strategy.

Simultaneously, imaging of the brain in infants with HIE has provided insight to clinicians in timing, location, and severity of injury. These novel insights have led to the development of neuroprotective strategies, and imaging techniques are now used as biomarkers of neurodevelopmental outcome.

In this review we will highlight the brain imaging techniques that have been used in term infants with HIE during the last $50 \mathrm{y}$.

\section{POSTMORTEM STUDIES}

Experimental studies in the 1950s have shown that severe perinatal hypoxia-ischemia could affect the brain resulting in cerebral palsy in surviving animals $(1,2)$. In the 1970s Myers et al. have demonstrated that different patterns of brain injury could be invoked in newborn rhesus monkeys. Basically, two patterns were identified, based on the duration and severity of the hypoxic-ischemic insult (3). The first pattern, occurring after so-called "total asphyxia" or "anoxia" consisted of injury to the deep gray matter and brain stem. In the most severe cases the whole brain was swollen.

The second pattern occurred after "partial asphyxia" or "prolonged hypoxia", and resulted in injury of the paracentral areas of the brain. At present, these lesions would be considered watershed lesions. In those days full intensive care could not be provided, and many animals died in the week after the hypoxic-ischemic insult. A few surviving animals showed signs of cerebral palsy.

These predominant patterns of injury could also be found in postmortem studies of human infants, and were described as "near-total brain injury", "injury of the basal ganglia and thalamus", and "watershed injury" $(4,5)$. Although perinatal asphyxia and ensuing brain injury were considered an important pathology of term infants, imaging studies have been sparse until the first studies using positron-emission tomography.

\section{POSITRON EMISSION TOMOGRAPHY}

Regional cerebral blood flow and positron emission tomography (PET) studies were performed in the 1980s in full-term infants with perinatal asphyxia (6). Volpe et al. studied 17 infants, of whom 15 were studied between day 3 and 5 (ref. (7)). Abnormalities were seen in the parasagittal brain areas, which were followed by an abnormal neurodevelopment during the first year of life with spastic quadriparesis and delayed development.

A few years earlier Lou et al. studied cerebral blood flow using ${ }^{133} \mathrm{Xe}$, demonstrating that low cerebral perfusion coincided with brain injury (8). 


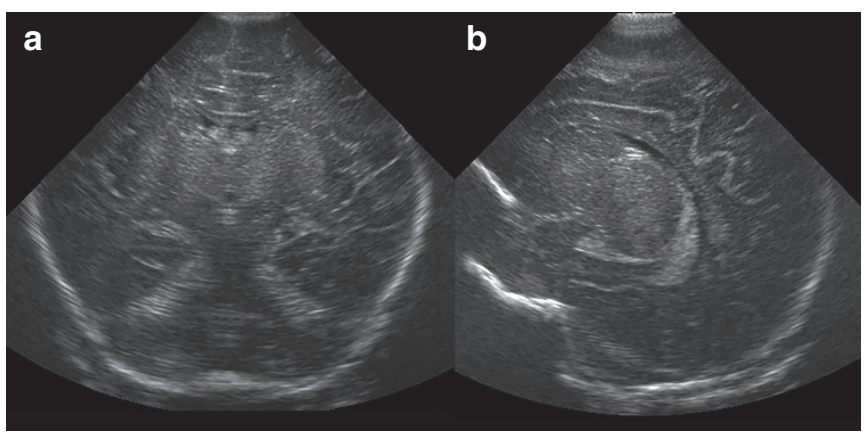

Figure 1. Cranial ultrasound on day 5 of a full-term neonate after severe perinatal asphyxia. (a) Coronal view. A so-called four column picture can be seen with increased echogenicity of the basal ganglia and thalami. In between these two echogenic areas the site of the posterior limb of the internal capsule is seen as an echolucent band. (b) Parasagittal view of the same patient.

In a later study increases in regional cerebral metabolic rate of glucose in the basal ganglia and thalamus were observed in infants who developed dyskinetic cerebral palsy $(9,10)$.

PET has not been used extensively in asphyxiated infants, and has mostly been combined with computed tomography (CT), which was introduced in the same period.

\section{COMPUTED TOMOGRAPHY}

In 1980, pneumoencephalographic findings in surviving infants with severe asphyxia were compared with CT-scans (11). In particular, cystic lesions in infants with multicystic encephalomalacia could be demonstrated with CT. Several other papers described abnormalities on CT scans and compared findings to postmortem examinations. Although detection of hemorrhages by CT was good, detection of ischemic brain damage noted at autopsy was poor (12). Only $49 \%$ were correctly diagnosed by CT prior to death. In severe cases diffuse hypodensity throughout the cerebral hemispheres, and subsequent areas of hypodensity in the cerebral cortex, as well as abnormalities in the subcortical white matter and basal ganglia were described (13). Interestingly, five out of six infants showed a thrombosis of the superior sagittal sinus on contrast enhancement. CT scans on the third day of life performed well compared with magnetic resonance imaging (MRI) concerning severe lesions in the deep gray matter, but performed worse for white matter and cortical injury (14).

CT has however several disadvantages. Poor spatial resolution, use of radiation, and movement of the patient away from the intensive care unit have led to increased use of cranial ultrasound (cUS). For the detection of hemorrhages, CT can be replaced by susceptibility weighted MRI. CT is still used in an acute situation, when neurosurgical intervention is considered (15). However, in many hospitals MRI can also be obtained in acute situations.

\section{CRANIAL ULTRASOUND}

In the 1980s cUS has been used extensively in preterm infants enabling clinicians to detect germinal matrix-intraventricular hemorrhage and cystic periventricular leukomalacia.
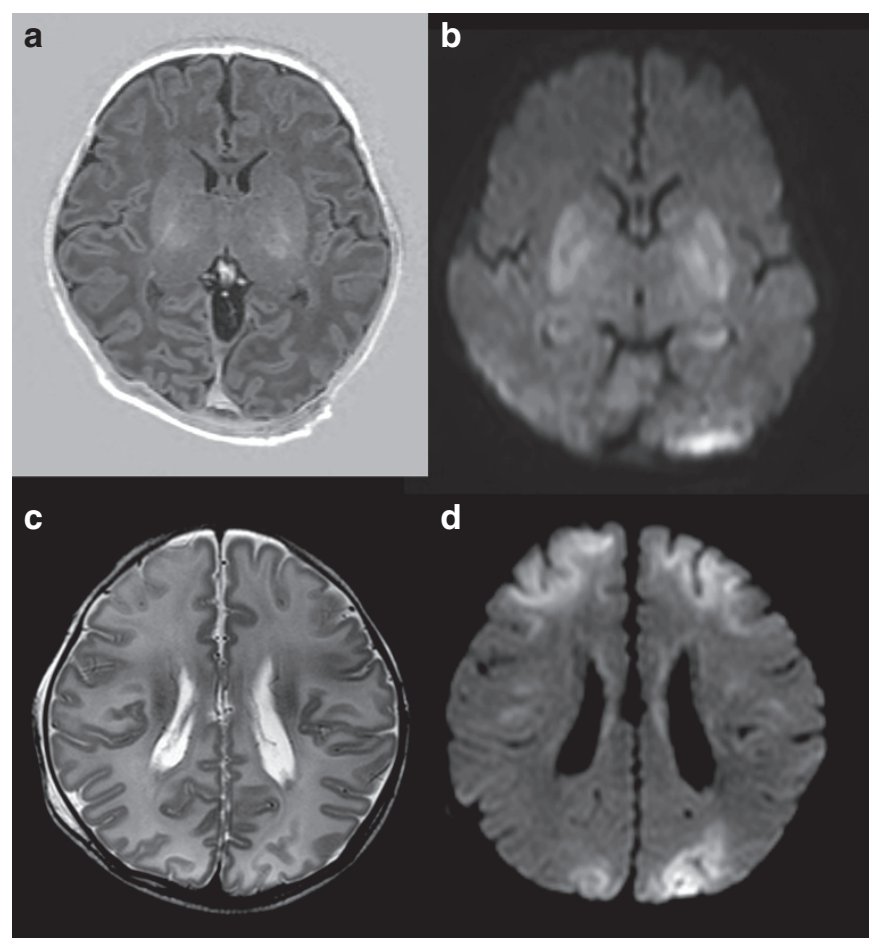

Figure 2. Different patterns of injury after perinatal asphyxia at term. Top row: axial T1-weighted magnetic resonance imaging (MRI) (a) and diffusion weighted imaging (DWI) (b) on day 4 in an infant with grade III encephalopathy. The T1-weighted MRI looks remarkably normal with some increased signal in the thalami, especially on the left. The signal in the posterior limb of the internal capsule appears to be present, especially on the right. This may be due to the fact that the MRI was performed early. Restricted diffusion is clearly seen on DWI in the basal ganglia bilaterally. Bottom row: axial T2-weighted MRI (c) and DWI (d) on day 5 of an infant with grade II encephalopathy. Signal changes can be seen in the watershed areas between anterior and middle, and also between the middle and posterior cerebral arteries. There is increased signal intensity and loss of the cortical ribbon on the T2-weighted MRI, especially in the right frontal lobe, but the abnormalities are easier to recognize with DWI.

In the early days of cUS the reported sensitivity for lesions in term neonates with HIE was good when imaging was performed beyond the first week of life (16). Abnormalities that could be identified with these first generation real-time sector scanners with a $5-\mathrm{MHz}$ mechanical sector transducer were changes in ventricular size, periventricular echogenicity, extra-axial fluid collections or intracranial hemorrhage. Also increased echogenicity in the thalami was detected (17) (Figure 1). When comparing cUS and MRI the incidence of changes in the basal ganglia/thalami and periventricular white matter was higher with MRI than with cUS, but cranial ultrasound scans identified all infants with a poor outcome (18).

Changes in cerebral blood flow were noted using Doppler techniques. A very low resistance index, corresponding to the "luxury hyperperfusion" described in animal experiments was associated with an adverse outcome (19).

Sensitivity and specificity of cUS were studied in a group of 34 full-term infants with HIE of whom 15 had a normal outcome. Sensitivity and specificity of cUS used within $6 \mathrm{~h}$ after birth for an adverse outcome were 42 and $60 \%$, respectively 


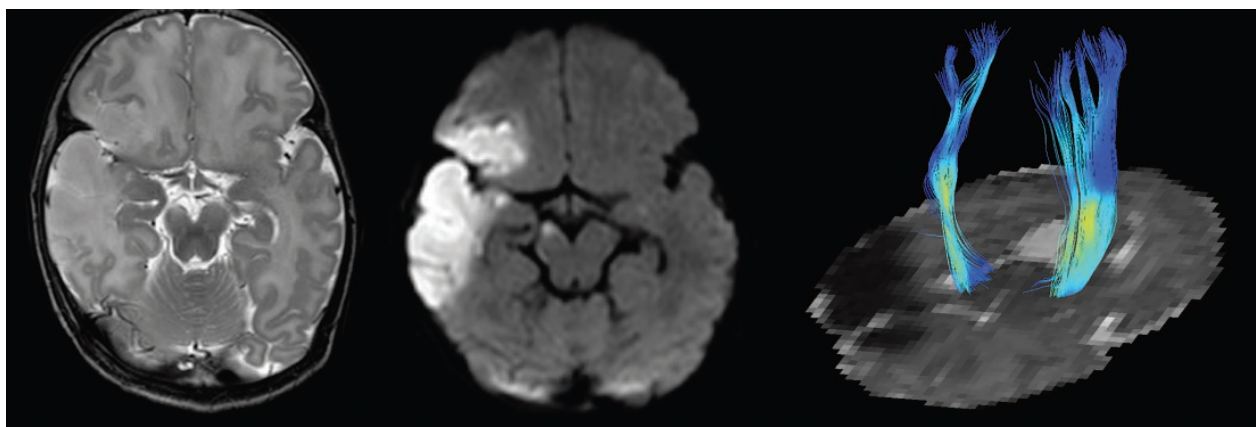

Figure 3. Axial T2-weighted magnetic resonance imaging (MRI) (left), diffusion weighted imaging (DWI) (middle) and tractography (right) on day 3 in an infant with a middle cerebral artery infarct and involvement of the ipsilateral corticospinal tract after mild perinatal asphyxia. An area of increased signal intensity with loss of gray white matter differentiation and increased signal intensity in the ipsilateral cerebral peduncle is seen on T2-weighted MRI. This is seen as restricted diffusion with DWI. Tractography demonstrates a clear asymmetry between the ipsilateral and contralateral corticospinal tracts. Courtesy of Dr. Niek van der Aa.
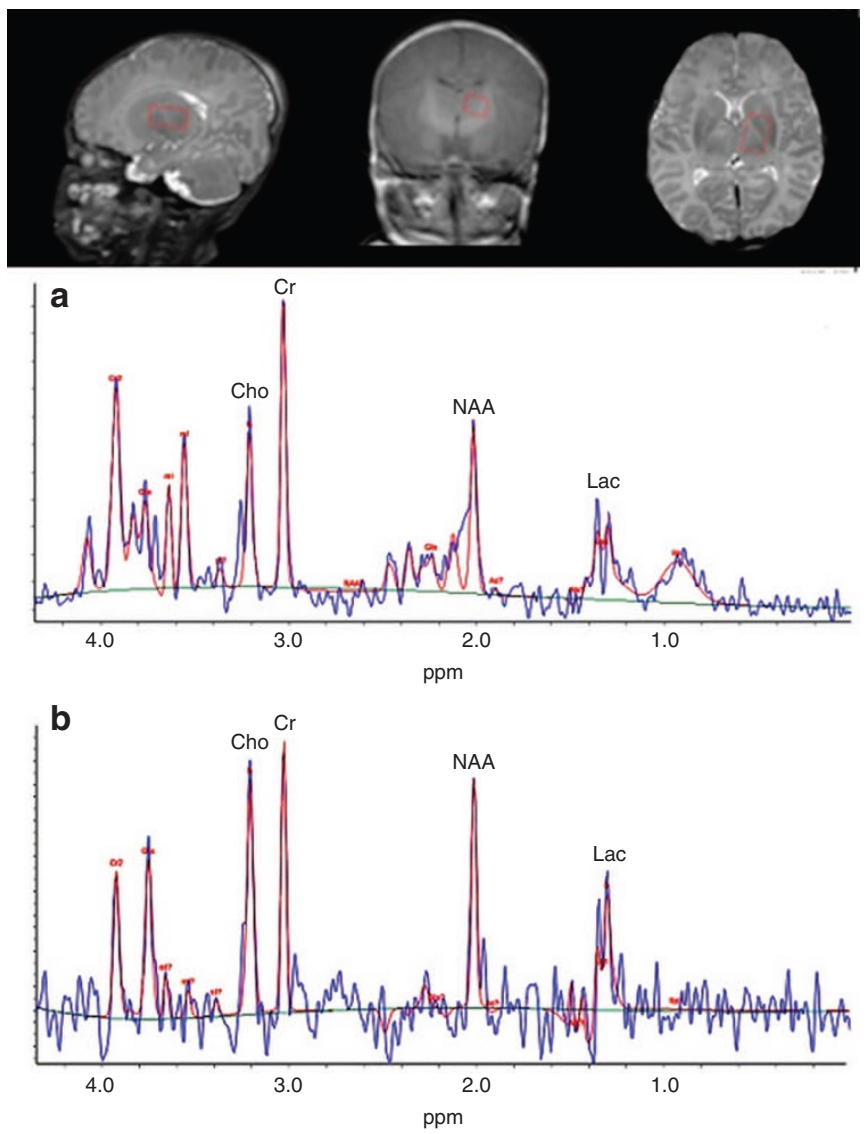

Figure 4. ${ }^{1}$ H-MRS of the basal ganglia and thalami on day 4 after perinatal asphyxia at term, showing the raw data (blue), fitted curve (red), and baseline (green). Short ( $38 \mathrm{~ms}$, a) and long $(288 \mathrm{~ms}$, b) echo times. A clear doublet at $1.33 \mathrm{ppm}$ can be seen which corresponds to the presence of lactate. This peak is not seen in healthy full-term infants. Other important peaks are $\mathrm{N}$-acetylaspartate (NAA), a marker of neurons, at $2.02 \mathrm{ppm}$, choline $(\mathrm{Cho})$ at $3.25 \mathrm{ppm}$, and creatine and phosphocreatine $(\mathrm{Cr})$ at $3.0 \mathrm{ppm}$. MRS, magnetic resonance spectroscopy.

(20). However, with the use of high resolution transducers the value of cUS for detecting intracranial abnormalities in infants with HIE who died was good (21).

More recent studies emphasized the importance of cUS in the term infant with HIE $(22,23)$. cUS immediately after birth can demonstrate congenital structural cerebral abnormalities, fetal brain injury, and detects abnormalities due to other causes of neonatal encephalopathy such as hypoplastic corpus callosum in cases of nonketotic hyperglycinemia, germinolytic cysts in mitochondrial or peroxisomal disorders, severe white matter echogenicity in molybdenum cofactor deficiency, also referred to as "HIE-mimics" (24).

In addition, several other forms of pathology leading to encephalopathy could be identified. Thalamic hemorrhages associated with an intraventricular hemorrhage in term infants could be identified easily, which can be caused by thrombosis of the deep venous system $(25,26)$. Ischemic infarcts in the vascular distribution of the middle cerebral artery could be detected, but recognition was not so good in the first days after birth and smaller cortical infarcts were missed $(27,28)$.

It has been suggested that cUS should be used for screening infants admitted to a NICU with neonatal encephalopathy (15). Increased echogenicity in the white matter seen on day of birth does suggest antenatal onset of neonatal encephalopathy. Abnormalities of the central gray nuclei and PAIS will be first recognized in the second half of the first week.

\section{MAGNETIC RESONANCE IMAGING}

MRI has been used in infants with HIE since the late 1980s $(29,30)$. After the development of MR sequences for newborn infants, detailed images of the brain structure could be obtained, and a scoring system for abnormalities after HIE was introduced (31). Injury to the basal ganglia and thalamus could be demonstrated, and the signal change in the posterior limb of the internal capsule became an important predictor of adverse outcome in term infants with perinatal asphyxia (32). Of important additional value was the introduction of diffusion weighted imaging (DWI), enabling detection of cell swelling ("cytotoxic edema") (33). Using DWI, changes in the thalamus during the first days after HIE, and basal ganglia slightly thereafter could be demonstrated, days before they could be identified with conventional T1 and T2 weighted imaging (34) (Figure 2). Furthermore, quantification of apparent diffusion coefficient $(\mathrm{ADC})$ values helped to further improve prediction of outcome after HIE (35). However, ADC values pseudonormalize after the first week, which restricts the value of DWI to the first week (36-38). 


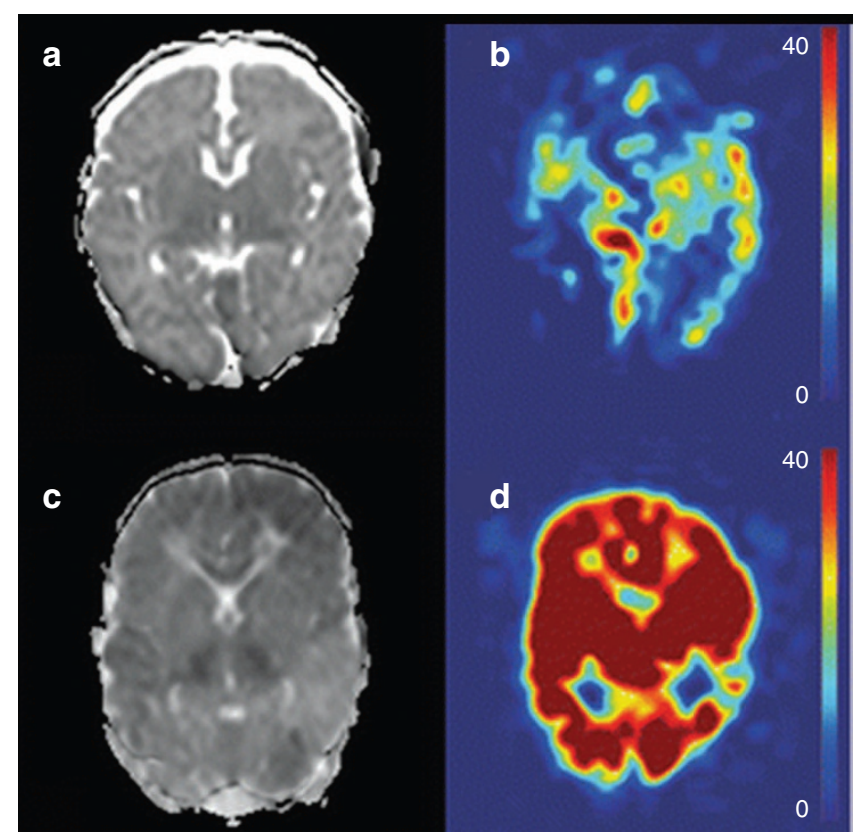

Figure 5. Arterial spin labeling in two full term infants. Top row: infant with hypoxic-ischemic encephalopathy (HIE) and favorable outcome. Left: apparent diffusion coefficient (ADC) map, right: arterial spin labeling (ASL) image. There are no areas of low signal intensity on the ADC map. On ASL, the perfusion is slightly higher in the central region, which one would expect. Bottom row: infant with an adverse outcome. Left: ADC map, showing areas of low signal intensity most clearly seen in the central grey nuclei and the frontal lobes; the ASL image shows pronounced hyperperfusion in the entire brain (52) (Springer, with permission).

Different patterns of injury after perinatal asphyxia that were seen with pathology such as watershed lesions of basal ganglia/thalamic lesions could now be visualized in vivo $(39,40)$. Use of MRI has helped to identify lesions in infants with HIE, emphasizing the role of perinatal asphyxia as a causal pathway for brain injury (41).

In addition, other lesions due to cerebral infections, and metabolic disorders (e.g., symptomatic hypoglycemia and molybdenum cofactor deficiency) leading to encephalopathy could be demonstrated. MRI might even be used as a biomarker of neurodevelopmental outcome in studies of neuroprotective strategies (42), and novel techniques such as tract based spatial statistics are currently explored (43).

Routine use of MRI has shown that small subdural hemorrhages are common. In a newborn with relatively mild HIE, these may contribute to seizures. In addition, techniques such as MR angiography and MR venography can visualize the vascular system noninvasively without the use of contrast. Use of MR venography has led to an increased detection of neonatal sinovenous thrombosis. Use of diffusion tensor imaging with or without tractography may help in identifying an asymmetry of the corticospinal tracts, and predict hemiplegia as has been shown in preterm infants (44) (Figure 3).

\section{MAGNETIC RESONANCE SPECTROSCOPY}

The first studies of brain metabolism were performed using phosphorous MR spectroscopy ( $\left.{ }^{31} \mathrm{P}-\mathrm{MRS}\right)$ (45). Alterations could be detected in brain tissue, with rapid improvement and secondary deterioration in brain energy metabolism after $6-8 \mathrm{~h}$. The concept of "secondary energy failure" was based on this phenomenon (46). Due to the limited spatial resolution at 1.5 and 3.0 Tesla of ${ }^{31} \mathrm{P}-\mathrm{MRS}$ no detailed images of brain metabolism could be obtained (31).P-MRS is still important in animal experiments of HIE, but the clinical value is limited at present. In contrast proton MR spectroscopy is still very important. Since its first use in the early 1990s (1),H-MRS of the basal ganglia and thalamus in HIE has been used to predict an adverse outcome $(47,48)$ (Figure 4). ${ }^{1} \mathrm{H}$-MRS is among the most powerful predictors after HIE (49). MR spectroscopy has also shown that metabolic derangements may persist for weeks after HIE (50). Using chemical shift imaging, also known as spectroscopic imaging, metabolites such as lactate could be demonstrated in vivo in neonatal stroke (51).

\section{ARTERIAL SPIN LABELING}

Recently, we, and others studied brain perfusion in infants with HIE using arterial spin labeling. Arterial hydrogen protons are inverted in the neck region and a labeled image is acquired after a certain time delay allowing the labeled spins to reach the brain tissue. Higher arterial spin labeling perfusion values in neonates with HIE, especially when seen in the basal ganglia and thalami, are associated with a worse neurodevelopmental outcome $(52,53)$ (Figure 5). The addition of arterial spin labeling to the scanning protocol might further improve prediction of outcome.

\section{EFFECTS OF TEMPERATURE ON IMAGING}

Hypothermia has been introduced $\sim 10$ y ago, and has become a standard neuroprotective strategy for full-term infants with severe perinatal asphyxia. Hypothermia has been shown to reduce injury to the basal ganglia and thalami and white matter, but in the presence of the known patterns of injury, the predictive value remained the same as prior to hypothermia. Hypothermia can modify imaging parameters, such as ADC values. The predictive value of DWI has been influenced by hypothermia. Although the predictive value for an adverse outcome is still excellent, cut-off values of ADC are lower, and pseudo-normalization slower after hypothermia. In addition, ADC values will be lower when imaging is performed during therapeutic hypothermia. Therapeutic hypothermia may also have an effect on results of ${ }^{1} \mathrm{H}$-MRS (54). Further studies are needed to specify these effects.

\section{FUTURE DEVELOPMENTS}

Recent studies have demonstrated that several PET techniques may be able to identify human stem cells in stroke patients (55), and discriminate between nonviable and viable (penumbra) tissue, which may be relevant for future trials studying neuroprotective strategies (56).

Whereas DWI and diffusion tensor imaging have become routine techniques to identify hypoxic-ischemic changes, diffusion kurtosis imaging, an extension to diffusion tensor imaging, which has enhanced sensitivity to microstructural changes compared with conventional diffusion tensor imaging 
parameters, is potentially more effective in cerebral gray matter changes (57).

A novel technique, which can be applied is quantitative sodium MRI. Sodium MRI could give spatial information on tissue viability and time information about onset of cerebral hypoxia-ischemia (58).

Besides these very sophisticated techniques, simple 2D measurements of T1 and T2 MR images can provide information relevant for neurodevelopmental outcome (59).

In conclusion, brain imaging during and after HIE has led to new insights in timing, location, and severity of injury. Cranial ultrasound should still be used for screening purposes during the first $5 \mathrm{~d}$ after resuscitation. MRI, in combination with proton MR spectroscopy has become the most specific and sensitive technique to identify lesions and predict outcome. In particular diffusion weighted MRI during the first week after resuscitation, can demonstrate patterns of injury comparable with postmortem examinations. A combination of cUS performed on admission and MRI during the first week allows distinguishing perinatal injury from antenatal injury. The changes in brain metabolism, and the concept of secondary energy failure have contributed to defining the therapeutic window of moderate hypothermia. Novel MR techniques, including tract-based spatial statistics and arterial spin labeling, may be used as biomarkers of outcome.

\section{STATEMENT OF FINANCIAL SUPPORT}

No financial support was obtained for this study. The authors do not have any conflict of interest.

\section{REFERENCES}

1. Windle WF. Neurological and psychological deficits from asphyxia neonatorum. Public Health Rep 1957;72:646-50.

2. Ranck JB Jr, Windle WF. Brain damage in the monkey, macaca mulatta, by asphyxia neonatorum. Exp Neurol 1959;1:130-54.

3. Myers RE. Two patterns of perinatal brain damage and their conditions of occurrence. Am J Obstet Gynecol 1972;112:246-76.

4. Squier W. Acquired Damage to the Developing Brain: Timing and Causation. Oxford, UK: Oxford University Press; 2002.

5. Volpe JJ. Neurology of the Newborn. Philadelphia: Saunders Book Company; 2008.

6. Volpe JJ, Pasternak JF. Parasagittal cerebral injury in neonatal hypoxicischemic encephalopathy: clinical and neuroradiologic features. J Pediatr 1977;91:472-6.

7. Volpe JJ, Herscovitch P, Perlman JM, Kreusser KL, Raichle ME. Positron emission tomography in the asphyxiated term newborn: parasagittal impairment of cerebral blood flow. Ann Neurol 1985;17:287-96.

8. Lou HC, Lassen NA, Friis-Hansen B. Impaired autoregulation of cerebral blood flow in the distressed newborn infant. J Pediatr 1979;94: $118-21$.

9. Blennow $M$, Ingvar $M$, Lagercrantz $H$, et al. Early $\left[{ }^{18} F\right] F D G$ positron emission tomography in infants with hypoxic-ischaemic encephalopathy shows hypermetabolism during the postasphyctic period. Acta Paediatr 1995;84:1289-95.

10. Thorngren-Jerneck K, Ohlsson T, Sandell A, et al. Cerebral glucose metabolism measured by positron emission tomography in term newborn infants with hypoxic ischemic encephalopathy. Pediatr Res 2001;49:495-501.

11. Taboada D, Alonso A, Olagüe R, Mulas F, Andrés V. Radiological diagnosis of periventricular and subcortical leukomalacia. Neuroradiol 1980;20:33-41.

12. Flodmark O, Becker LE, Harwood-Nash DC, Fitzhardinge PM, Fitz CR, Chuang SH. Correlation between computed tomography and autopsy in premature and full-term neonates that have suffered perinatal asphyxia. Radiology 1980;137(1 Pt 1):93-103.
13. Voorhies TM, Lipper EG, Lee BC, Vannucci RC, Auld PA. Occlusive vascular disease in asphyxiated newborn infants. J Pediatr 1984;105:92-6.

14. Chau V, Poskitt KJ, Sargent MA, et al. Comparison of computer tomography and magnetic resonance imaging scans on the third day of life in term newborns with neonatal encephalopathy. Pediatrics 2009;123:319-26.

15. Barnette AR, Horbar JD, Soll RF, et al. Neuroimaging in the evaluation of neonatal encephalopathy. Pediatrics 2014;133:e1508-17.

16. Babcock DS, Ball W Jr. Postasphyxial encephalopathy in full-term infants: ultrasound diagnosis. Radiology 1983;148:417-23.

17. Siegel MJ, Shackelford GD, Perlman JM, Fulling KH. Hypoxic-ischemic encephalopathy in term infants: diagnosis and prognosis evaluated by ultrasound. Radiology 1984;152:395-9.

18. Rutherford MA, Pennock JM, Dubowitz LM. Cranial ultrasound and magnetic resonance imaging in hypoxic-ischaemic encephalopathy: a comparison with outcome. Dev Med Child Neurol 1994;36:813-25.

19. Archer LN, Levene MI, Evans DH. Cerebral artery Doppler ultrasonography for prediction of outcome after perinatal asphyxia. Lancet 1986;2:1116-8

20. Eken P, Toet MC, Groenendaal F, de Vries LS. Predictive value of early neuroimaging, pulsed Doppler and neurophysiology in full term infants with hypoxic-ischaemic encephalopathy. Arch Dis Child Fetal Neonatal Ed 1995;73:F75-80.

21. Eken P, Jansen GH, Groenendaal F, Rademaker KJ, de Vries LS. Intracranial lesions in the full-term infant with hypoxic ischaemic encephalopathy: ultrasound and autopsy correlation. Neuropediatrics 1994;25:301-7.

22. Epelman M, Daneman A, Halliday W, Whyte H, Blaser SI. Abnormal corpus callosum in neonates after hypoxic-ischemic injury. Pediatr Radiol 2012;42:321-30.

23. Dinan D, Daneman A, Guimaraes CV, Chauvin NA, Victoria T, Epelman M. Easily overlooked sonographic findings in the evaluation of neonatal encephalopathy: lessons learned from magnetic resonance imaging. Semin Ultrasound CT MR 2014;35:627-51.

24. de Vries LS, Cowan FM. Evolving understanding of hypoxic-ischemic encephalopathy in the term infant. Semin Pediatr Neurol 2009;16: 216-25.

25. De Vries LS, Smet M, Goemans N, Wilms G, Devlieger H, Casaer P. Unilateral thalamic haemorrhage in the pre-term and full-term newborn. Neuropediatrics 1992;23:153-6.

26. Govaert P, Achten E, Vanhaesebrouck P, De Praeter C, Van Damme J. Deep cerebral venous thrombosis in thalamo-ventricular hemorrhage of the term newborn. Pediatr Radiol 1992;22:123-7.

27. de Vries LS, Groenendaal F, Eken P, van Haastert IC, Rademaker KJ, Meiners LC. Infarcts in the vascular distribution of the middle cerebral artery in preterm and fullterm infants. Neuropediatrics 1997;28:88-96.

28. Cowan F, Mercuri E, Groenendaal F, et al. Does cranial ultrasound imaging identify arterial cerebral infarction in term neonates? Arch Dis Child Fetal Neonatal Ed 2005;90:F252-6.

29. Barkovich AJ, Truwit CL. Brain damage from perinatal asphyxia: correlation of MR findings with gestational age. AJNR Am J Neuroradiol 1990;11:1087-96.

30. Pasternak JF, Predey TA, Mikhael MA. Neonatal asphyxia: vulnerability of basal ganglia, thalamus, and brainstem. Pediatr Neurol 1991;7:147-9.

31. Barkovich AJ, Westmark K, Partridge C, Sola A, Ferriero DM. Perinatal asphyxia: MR findings in the first 10 days. AJNR Am J Neuroradiol 1995;16:427-38.

32. Rutherford MA, Pennock JM, Counsell SJ, et al. Abnormal magnetic resonance signal in the internal capsule predicts poor neurodevelopmental outcome in infants with hypoxic-ischemic encephalopathy. Pediatrics 1998;102(2 Pt 1):323-8.

33. Cowan FM, Pennock JM, Hanrahan JD, Manji KP, Edwards AD. Early detection of cerebral infarction and hypoxic ischemic encephalopathy in neonates using diffusion-weighted magnetic resonance imaging. Neuropediatrics 1994;25:172-5.

34. Robertson RL, Ben-Sira L, Barnes PD, et al. MR line-scan diffusionweighted imaging of term neonates with perinatal brain ischemia. AJNR Am J Neuroradiol 1999;20:1658-70.

35. Alderliesten T, de Vries LS, Benders MJ, Koopman C, Groenendaal F. MR imaging and outcome of term neonates with perinatal asphyxia: value 
of diffusion-weighted MR imaging and ${ }^{1} \mathrm{H}$ MR spectroscopy. Radiology 2011;261:235-42.

36. Rutherford M, Counsell S, Allsop J, et al. Diffusion-weighted magnetic resonance imaging in term perinatal brain injury: a comparison with site of lesion and time from birth. Pediatrics 2004;114:1004-14.

37. Bednarek N, Mathur A, Inder T, Wilkinson J, Neil J, Shimony J. Impact of therapeutic hypothermia on MRI diffusion changes in neonatal encephalopathy. Neurology 2012;78:1420-7.

38. McKinstry RC, Miller JH, Snyder AZ, et al. A prospective, longitudinal diffusion tensor imaging study of brain injury in newborns. Neurology 2002;59:824-33.

39. de Vries LS, Groenendaal F. Patterns of neonatal hypoxic-ischaemic brain injury. Neuroradiology 2010;52:555-66.

40. Miller SP, Ramaswamy V, Michelson D, et al. Patterns of brain injury in term neonatal encephalopathy. J Pediatr 2005;146:453-60.

41. Cowan F, Rutherford M, Groenendaal F, et al. Origin and timing of brain lesions in term infants with neonatal encephalopathy. Lancet 2003;361: $736-42$.

42. Shankaran S, McDonald SA, Laptook AR, et al.; Eunice Kennedy Shriver National Institute of Child Health and Human Development Neonatal Research Network. Neonatal magnetic resonance imaging pattern of brain injury as a biomarker of childhood outcomes following a trial of hypothermia for neonatal hypoxic-ischemic encephalopathy. J Pediatr 2015;167:987-93.e3.

43. Porter EJ, Counsell SJ, Edwards AD, Allsop J, Azzopardi D. Tract-based spatial statistics of magnetic resonance images to assess disease and treatment effects in perinatal asphyxial encephalopathy. Pediatr Res 2010;68:205-9.

44. Roze E, Benders MJ, Kersbergen KJ, et al. Neonatal DTI early after birth predicts motor outcome in preterm infants with periventricular hemorrhagic infarction. Pediatr Res 2015;78:298-303.

45. Wyatt JS, Edwards AD, Azzopardi D, Reynolds EO. Magnetic resonance and near infrared spectroscopy for investigation of perinatal hypoxicischaemic brain injury. Arch Dis Child 1989;64(7 Spec No):953-63.

46. Lorek A, Takei Y, Cady EB, et al. Delayed ("secondary") cerebral energy failure after acute hypoxia-ischemia in the newborn piglet: continuous 48-hour studies by phosphorus magnetic resonance spectroscopy. Pediatr Res 1994;36:699-706.
47. Peden CJ, Rutherford MA, Sargentoni J, Cox IJ, Bryant DJ, Dubowitz LM. Proton spectroscopy of the neonatal brain following hypoxic-ischaemic injury. Dev Med Child Neurol 1993;35:502-10.

48. Groenendaal F, Veenhoven RH, van der Grond J, Jansen GH, Witkamp TD, de Vries LS. Cerebral lactate and $\mathrm{N}$-acetyl-aspartate/choline ratios in asphyxiated full-term neonates demonstrated in vivo using proton magnetic resonance spectroscopy. Pediatr Res 1994;35:148-51.

49. Thayyil S, Chandrasekaran M, Taylor A, et al. Cerebral magnetic resonance biomarkers in neonatal encephalopathy: a meta-analysis. Pediatrics 2010;125:e382-95.

50. Hanrahan JD, Cox IJ, Edwards AD, et al. Persistent increases in cerebral lactate concentration after birth asphyxia. Pediatr Res 1998;44:304-11.

51. Groenendaal F, van der Grond J, Witkamp TD, de Vries LS. Proton magnetic resonance spectroscopic imaging in neonatal stroke. Neuropediatrics $1995 ; 26: 243-8$.

52. De Vis JB, Hendrikse J, Petersen ET, et al. Arterial spin-labelling perfusion MRI and outcome in neonates with hypoxic-ischemic encephalopathy. Eur Radiol 2015;25:113-21.

53. Wintermark P. Injury and repair in perinatal brain injury: Insights from non-invasive MR perfusion imaging. Semin Perinatol 2015;39:124-9.

54. Cady EB, D'Souza PC, Penrice J, Lorek A. The estimation of local brain temperature by in vivo ${ }^{1} \mathrm{H}$ magnetic resonance spectroscopy. Magn Reson Med 1995;33:862-7.

55. Rueger MA, Schroeter M. In vivo imaging of endogenous neural stem cells in the adult brain. World J Stem Cells 2015;7:75-83.

56. Bunevicius A, Yuan H, Lin W. The potential roles of ${ }^{18} \mathrm{~F}$-FDG-PET in management of acute stroke patients. Biomed Res Int 2013;2013:634598.

57. Umesh Rudrapatna S, Wieloch T, Beirup K, et al. Can diffusion kurtosis imaging improve the sensitivity and specificity of detecting microstructural alterations in brain tissue chronically after experimental stroke? Comparisons with diffusion tensor imaging and histology. Neuroimage 2014;97:363-73.

58. Madelin G, Lee JS, Regatte RR, Jerschow A. Sodium MRI: methods and applications. Prog Nucl Magn Reson Spectrosc 2014;79:14-47.

59. Spring in 't Veld LG, de Vries LS, Alderliesten T, Benders MJ, Groenendaal F. Serial 1- and 2-dimensional cerebral MRI measurements in full-term infants after perinatal asphyxia. Neonatology 2016;110:27-32. 